\title{
O ÚLTIMO PIRANDELLO E SUA PERSONAGEM-ATRIZ
}

O decênio 1925-1936 será a fase mais conturbada e complexa na experiência artística e existencial de Pirandello: o dramaturgo se envolve com os problemas concretos do fazer teatral, questiona a própria poética que o atormentou a vida inteira e, principalmente, mantém com a jovem atriz Marta Abba uma ambígua relação pessoal e artística. Escassamente discutida, se comparada ao número de estudos da fase imediatamente anterior, esta dramaturgia tardia irá testemunhar uma grande explosão de contribuições críticas, na Itália, a partir de 1995 (ano de publicação do epistolário

Pirandello-Abba). Mas, no Brasil, sua gênese ainda permanece substancialmente desconhecida.

Palavras-chave: Luigi Pirandello, Marta Abba, teatro autobiográfico, Vamp Virtuosa, personagem-atriz.

Abstract

The years between 1925 and 1936 were the most disturbed and complex ones in Pirandello's artistic and existential experience: in that period, the playwright was engaged with real problems concerning theatrical making, questioning his own poetics - something that was around for his whole life - and, above all, kept a very ambiguous personal and artistic relationship with the young actress Marta Abba. Scarcely investigated if compared with the number of studies related to the earlier periods, this late production by Pirandello would witness an enormous explosion of critical studies in Italy from 1995 on (the publication year of the letters Pirandello - Abba). On the contrary, its genesis remains absolutely unknown in Brazil.

Keywords: Luigi Pirandello, Marta Abba, autobiographical theatre, Virtuous Vamp, character actress. 
$\mathrm{M}$ uito se falou sobre o teatro de Luigi Pirandello(1867-1936) e pouco se explicou sobre sua última estação dramatúrgica, especialmente os dramas escritos para a atriz Marta Abba (1900-1988), principal intérprete e musa inspiradora de sua obra tardia. No Brasil, os estudos ainda se orientam principalmente em torno da assim denominada segunda fasedesua dramaturgia-quedidaticamente se abre com Cosi è (si vi pare), em 1917, e que se fecha em 1924 (antes da tessitura de Diana e la Tuda em 1925). Em sua grande maioria, as leituras giram em torno do relativismo pirandelliano, reflexo de uma condição burguesa fraturada, identificando toda a sua obra teatral na ideia de oposição entre um indivíduo isolado e um corpo social; análise que se impôs ao final dos anos cinquenta a partir de um longo artigo de Mario Baratto intitulado Le théâtre di Pirandello. Uma leitura que de fato serviu para organizar um primeiro retrato do autor, mas que, todavia, nos oferece um quadro apenas parcial, já que não chega a contemplar a obra tardia.

A incompreensão de sua última produção permanece com Arcangelo Leone de Castris, no livro Storia di Pirandello de 1962 que chega a liquidar um texto capital como Questa sera si recita a sogetto, como exemplo de uma "involução" de uma desvitalização artística que leva o autor da "poesia a técnica", definindo a peça como simples postulado de artifícios teatrais sem valor ideológico. $\mathrm{Na}$ medida em que Pirandello se afasta de sua primitiva inspiração - de poeta da condição trágica da sociedade burguesa, da consciência dividida - e busca experimentar evasões surrealistas, fugas ao irracional, na crença

1 Martha Ribeiro é Diretora teatral e Professora Adjunta do Departamento de Artes da Universidade Federal Fluminense, Instituto de Artes e Comunicação Social (IACS), e do Programa de Pós-Graduação em Ciência da Arte da UFF. É Doutora em Teoria e História Literária (UNICAMP-IEL), com período sanduíche na Università di Torino. Realizou Pós-Doutorado na UNICAMP-IAR. Em suas publicações, destaca-se o livro "Luigi Pirandello: um teatro para Marta Abba”, da Editora Perspectiva. da existência de uma realidade superior, ou de um "corpo sem nome", como desejado pela Ignota de Come tu mi vuoi (1929), seu teatro é visto como decadente e indigno de qualquer exegese crítica. Só no final dos anos 60, é que se vê uma recuperação dos três mitos pirandellianos (La nuova colonia, Lazzaro, I giganti della montagna) a partir do livro Il teatro mitico di Pirandello de Marziano Guglielminetti. Mas ainda havia todo um filão dramatúrgico que permanecia excluído das análises críticas: de Diana e la Tuda, passando pela L'amica delle mogli, Trovarsi, Quando si è qualcuno e Come tu mi vuoi é todo um teatro que substancialmente foi posto de lado pela crítica, sendo recuperado, mais solidamente, e sem os preconceitos que insistentemente rebaixava este teatro em confronto com a produção anterior, somente a partir dos anos 80 , com as análises pioneiras de Roberto Alonge, Giovanni Macchia e Massimo Castri.

Esta dramaturgia permaneceu por longos anos analisada como desviante do verdadeiro núcleo poético do dramaturgo, pois parecia que o autor retornava a uma ideia de teatro já superada, recuperando um tipo de relação impossível (que se quer invisível) entre personagem e ator. Aquela nódoa obscura de psicologia e de interioridade, portador da ideologia e da prática naturalista, o personagem dramático, voltava a estabelecer na dramaturgia pirandelliana do nosso uma relação com o ator baseada no mito da transparência, isto é, na ilusão de que entre ator e personagem se estabelece uma relação total de superposição, e até mesmo de fusão, herança de um teatro naturalista, e, consequentemente, um dos maiores obstáculos aos ideais de liberdade e de autonomia plena da cena; em sua vertente formalista. Contemporaneamente aos reformadores teatrais, Pirandello tinha consciência da problemática da relação personagem-ator para a cena teatral e da necessidade de se estabelecer uma nítida separação entre as identidades. No ensaio Illustratori, attori e traduttori (1907) é possível verificar o engajamento 
na direção de uma separação total entre as partes, mas a linha de comunicação pretendida por Pirandello se dava entre o personagem e o espectador, o ator seria nada mais do que um terceiro elemento incômodo na fruição da obra de arte.

Embora a autonomia do personagem em relação ao ator seja reivindicada tanto teoricamente quanto poeticamente, isto é, no texto Sei personaggi in cerca d'autore (1921), nos argumentos da impossibilidade de se representar o drama, se reconhece os pressupostos do ensaio Illustratori, attori e traduttori, se verifica em Pirandello uma nostalgia em relação ao mito da transparência. Ouso da fórmula "teatro no teatro" estabelece coincidências entre o mundo ficcional e o mundo real: o espaço descrito pelo drama é o mesmo espaço do palco real e os atores se duplicam em cena, representando eles mesmos: ou seja, atores. Mas se existe a consciência de uma distância entre ator e personagem, na prática se verifica uma espécie de tentação em atingir com o teatro, a partir do personagem, aquela autenticidade profunda que a experiência cotidiana nos nega. Na peça Sei personaggi se verifica uma forte tensão entre a forma dramática e o conteúdo do texto, pois enquanto o discurso dos seis personagens desenvolve a ideia de uma irremediável distância entre a cena (realidade material) e o texto (realidade fantástica), através do qual os personagens rejeitam qualquer tentativa de representação por parte dos atores, na forma dramática se observa uma tentativa de recuperação da transparência perdida.

Com Pirandello, a perspectiva em relação à interpretação se assemelha ao modelo naturalista, mas com duas fundamentais diferenças: uma nova ideia de personalidade humana, elaborada no ensaio L'umorismo (1908), e a visão de superioridade do personagem em relação ao ser humano. No palco, o ator não deve se transformar em uma figura humana, deve evocar um ser diferente, estranho, que vive em uma outra esfera de realidade. Não é só o físico do ator que se diferencia do personagem, sua natureza é que é feita de outra matéria e que por isso arrisca ocultar o caráter profundo e essencial da criatura fantástica. Se é possível falar de uma teoria atorial pirandelliana diremos que, ao inverso do naturalismo, mas de efeito semelhante, sua dramaturgia propõe a possessão do intérprete pelo personagem dramático. Não será o ator a entrar no personagem, mas o personagem a entrar no ator. O teatro como local privilegiado do encontro e do desencontro entre uma realidade superior e o mundo material da cena. Palco onde se verifica ao mesmo tempo uma distância e uma ilusão de identificação, onde a cena oscila entre a ficção, a tentativa de representação, e a instalação do real, na idealização de possessão do ator pelo personagem. Sem abandonar a nostalgia utópica do mito da transparência, mas mantendo a diferença entre as identidades, Pirandello faz do corpo do ator não uma marionete, e sim um fantasma; mito que permeia não só Sei personaggi, mas, implicitamente ou explicitamente, toda sua obra posterior.

Osujeitoisolado, aconsciência dividida, reflexo de um mundo também em crise, e da própria visão do autor sobre o mundo, nasce na poética do humorismo: ao valor de integração social o dramaturgo contrapõe o homem só; à compostura da forma social o phatos, o irromper da paixão, sempre associado a uma profusão de raciocínios desagregadores. Mas, na medida em que o processo de isolamento do personagem humorístico atinge um grau extremo, causando a perda irremediável de sua identidade (como exemplo a Sra. Ponza de Cosi è (si vi pare), de 1917), Pirandello se vê numa encruzilhada: o maneirismo do seu próprio estilo. E é neste momento de crise que um outro personagem, mais humano, menos cerebral, precisa nascer: se trata de uma tentativa de recuperação daquela força original, mágica, irreal, mística e mais positiva que pertencia a um teatro de outrora: da nostalgia de uma transparência perdida, o autor, em sua última fase, faz do teatro um palco de celebração do poder da arte de ser vida, de produzir vida. O que 
se pode mensurar no percurso artístico de Pirandello é uma via que vai da negação do teatro enquanto forma de arte, poética do humorismo, ao entendimento do teatro enquanto um ato de vida, de produção de vida. Claro que não se trata do reflexo da vida cotidiana, pois a vida que se produz no palco seria de uma natureza mais autêntica, mais verdadeira que a realidade social, esta sim um espetáculo da aparência.

Há pouco mais de uma década, após a publicação do epistolário Lettera a Marta $A b b a$, em 1995, foi possível conhecer o verdadeiro "caderno" de criação da dramaturgia pirandelliana do último período. Além de trazer importantes informações sobre a situação teatral italiana da época, sua crise estrutural e os projetos de reforma, obviamente que sob o ponto de vista do dramaturgo, as cartas iluminam uma importante fase de sua vida, o exílio voluntário, durante o qual Pirandello se aproximou tanto do cinema quanto da cena contemporânea europeia. Mas, o principal motivo de sua essencialidade para o estudo de sua dramaturgia tardia é o fornecimento de evidências quanto ao fundo autobiográfico de sua última produção teatral. Fragmentos do epistolário refluem para as peças e viceversa; os textos dedicados e escritos para a atriz são cuidadosamente analisados nas cartas, descritos na sua gênese $e$ no seu desenvolvimento, sempre com

2 Roberto Alonge (1997, p. 104-105) já destacou a coincidência literária existente entre a fala do velho poeta ao final do segundo ato de Quando si è qualcuno, datado de set-out. de 1932, com um fragmento de carta de Pirandello a Marta Abba datado de 25 de janeiro de 1931. Trata-se exatamente do mesmo texto. Abaixo transcrevemos ambos os fragmentos em língua italiana, sem tradução, para não ferir a impressionante equivalência da trama verbal:

$\underline{\text { I- Quando si è qualcuno }}$

tu non la sai: uno specchio - scoprircisi d'improvviso - e la desolazione di vedersi che uccide ogni volta lo stupore di non ricordarsene più - e la vergogna dentro, [...] il cuore ancora giovine e caldo. (Luigi Pirandello, Quando si è qualcuno, in Maschere Nude, vol. IV, Milano, Mondadori, 2007, p. 696).

\section{II - Carta de 25 janeiro de 1931}

tu non sai che scoprendomi per caso d'improvviso a uno specchio, la desolazione di vedermi [...] uccide ogni volta in me lo stupore di non ricordarmene più. [...] provo un senso di vergogna del mio cuore ancora giovanissimo e caldo. (Luigi Pirandello, Lettera a Marta Abba, Milano, Mondadori, 1995, p. 622). a participação ativa da atriz. $^{2}$ Seja no intercâmbio entre fragmentos de carta e obra dramática, seja na repetição obsessiva de temas, seja na recorrente descrição física dos personagens femininos, o que se vê refletido neste teatro é fundamentalmente sua relação artística e pessoal com a atriz Marta Abba.

$\mathrm{Na}$ visão do dramaturgo, Marta era a única intérprete capaz de unir em espetáculo a invenção fantástica com a materialidade do palco. No palco, a atriz conseguia aquele equilíbrio fundamental entre o épico (distância irremediável que existe entre o personagem e o ator) e um estado de identificação total, absoluta, de autonegação, de auto-esvaziamento, fundamental para atrair para o palco o personagem dramático; segundo a poética de Pirandello. A impostação cênica da atriz parece ao dramaturgo singularmente consoante com os traços de sua própria dramaturgia. E sobre dois fatos a crítica da época, tanto a positiva quanto a negativa, concordavam: que a interpretação da atriz era intensa, imediata e apaixonada. E que junto a este arrebatamento, se notava um distanciamento, uma frieza inesperada e inexplicável. Dois estados contraditórios de atuação que emergia de uma interpretação fraturada entre estados mentais diferentes: de identificação e de estranhamento, uma atuação que se equilibrava entre o metafísico e o realismo. Com uma extrema mobilidade expressiva, a atriz conseguia mudar de um estado emotivo a outro bruscamente, sem transição. Seu estilo traduzia materialmenteocomportamento do personagem pirandelliano, sua consciência dilacerada. As pausas, as rupturas de tom, a voz arrastada, os movimentos bruscos e a carga emotiva que Marta emprestava a dos personagens aproximava sua natureza ao dos personagens pirandellianos; o que levou Pirandello a identifica-la, inclusive fisicamente, com as figuras fantásticas de sua criação. Marta parecia aos olhos do Maestro reunir em carne e em espírito a natureza particularíssima de seus personagens.

Com ritmos contraditórios, entonações rasgadas, gestos fortes, inflexíveis, 
somados a uma docilidade e a uma "frieza" desconcertantes, Marta Abba estabeleceu entre a obra de um dos maiores escritores teatrais do século $X X$ e sua arte de intérprete uma relação excepcional, pois íntima, necessária e efetiva. Com a atriz, as criaturas pirandellianas, seus contrasensos físicos e morais, conquistaram uma verdade tangível. Se Pirandello dramaturgo encontrou em Marta sua intérprete, como de fato ocorreu, a atriz, em contato com o texto pirandelliano, também descobriu o seu próprio "espaço" artístico, isto é, sua originalidade atorial. Interpretando os personagens femininos pirandellianos, Marta termina por inspirar o nascimento de um outro personagem: no lugar do personagem humorístico "cerebral" se impõe nesta dramaturgia tardia uma figura de mulher complexa e misteriosa, que embora muito sensual e desejável não se deixa possuir, permanecendo assim distante, etérea e sublimada. Esta nova personagem, nascida a partir do encontro de Pirandello com a atriz, foi por nós denominada de Vamp Virtuosa: Tuda, Marta, Ignota, Veroccia, Sara, Donata, imagem física e idealizada da atriz Abba, são mulheres ruivas, jovens, belas, sensuais, eroticamente fascinantes, mas sexualmente inacessíveis. ${ }^{3}$ Donas de um caráter contraditório e uma personalidade camaleônica, esta vamp virtuosa é uma mulher atraente e eroticamente fascinante, mas que não pode ter o amor, sob pena de sua catástrofe e ruína.

A vamp virtuosa é um tipo de mulher que, malgrado seu comportamento de mulher fatal, não é uma devoradora de homens. Ainda que possua o corpo sensual da vamp, ela possui o coração de uma virgem (ou o de uma menina). Ou ela se torna vítima do homem que ela mesma seduziu, ou deve renunciar à própria sexualidade,escolhendoa veneradavirtude. A dualidade da fêmea fatal construída por Marta, se verifica no uso de uma voz rouca, acentuada, sussurrante, que corresponde

3 Respectivamente: Diana e la Tuda; Lamica delle mogli; Come tu mi vuoi; Quando si è qualcuno; La nuova colonia; Trovarsi. a um tipo de mulher sensual, indolente e maliciosa, em contraste com arroubos infantis nos momentos de felicidade e na nostálgica busca de uma pureza perdida. É a partir da sublimação deste tipo, forjado por Marta Abba tanto no palco, como na vida real, que Pirandello irá se inspirar para criar um novo perfil feminino: uma mulher jovem, sensual, plena de desejo e de vida, mas que, no entanto, está proibida de viver sua sexualidade livremente. ${ }^{4}$ Essas personagens, nascidas sob o influxo de Marta, apesar de toda a beleza e fascínio, escolhem por vontade própria romper com a vida material, isto é, elas recusam viver a vida de uma mulher comum, criando para si mesmas, a partir da fantasia, uma nova realidade, mais onírica e mais destacada de sua própria condição feminina. Sem estar completamente pronta para se aventurar no erotismo sem culpa, medo ou pudor, a experiência erótica da vamp virtuosa sempre será frustrante. Se ela se entregar a "viscosidade" da vida material, sua punição será a perda de seu "encantamento" e ela se verá constrangida a se ver repetindo o histórico papel de mulher passiva e dependente ou mesmo viver a sua desvalorização moral. Por sua natureza "superior", espiritual e etérea, esta mulher será capaz de sublimar Eros. Se Pirandello a deixa viver ou pensar no amor é somente para tiranizá-la: deixando ela se envolver, o dramaturgo retira o véu do mistério que encobria esta mulher divinamente intocável, faz com que o homem a despreze

4 Basta abrirmos os dois epistolários para verificarmos que Marta se adequou aos pedidos mudos do Maestro, aceitando uma vida vivida somente em função do teatro. Apesar de bela, jovem e exuberante, Marta descreve não ter uma vida social ativa, sua vida é só o trabalho e nada de divertimento. Do teatro ela vai para casa dormir cedo. Como um sacerdote, ou como uma "boa menina", Marta aceita o jogo tirânico do dramaturgo, e tanto na vida como na arte, ela corresponde à imagem que Pirandello construiu a partir de seu desejo. Como observado por Pietro Frassica, Marta sabia que para o escritor era um sofrimento não tê-la por perto, o que Pirandello deixa bem claro nas cartas. A atriz provavelmente era consciente de que a proibição da sexualidade, dissimulada no jogo ambivalente de renúncia da vida, era uma manipulação de Pirandello sobre o seu desejo. Escreve Marta em 16 de agosto de 1931: "Ả noite, já na cama. Mas, como me divirto tão pouco ficando na rua, realmente não me custa nada fazer deste jeito" (Cf Marta Abba, Caro Maestro, op. cit., p. 210). 
pelo que ela é, para então, ao final da peça, "levantá-la do chão" mostrando como único caminho a via sublime da arte (ou a renuncia da sexualidade).

Todas as personagens que nascem a partir da imagem idealizada de Marta, possuem como característica unificadora um modus espetacular, ou seja, elas são mulheres que se doam em espetáculo. Como uma atriz, elas se mostram ao outro, ao mesmo tempo em que não revelam nada sobre elas mesmas. Misteriosas e etéreas, vivas e ausentes, humanas e divinas, elas se deixam transformar naquilo que a imaginação de cada um criou para ela segundo o seu próprio desejo. Como elas, Marta Abba era também uma atriz, e como atriz ela também é reveladora de um imaginário social. Se a imagem de uma atriz se perde entre mil reflexos, sem dúvida nenhuma ela está no centro de uma reserva convergente de imagens sociais significativas; o que explica porque escritores, pintores, filósofos se interessam apaixonadamente por elas. E no imaginário pirandelliano, será uma única atriz a incendiar seus sonhos: a camaleônica Marta Abba, musa inspiradora, mulher real, existente, tão necessária quanto absolutamente ausente. E o Maestro não faltará a sua musa, não deixará de escrever sobre e para a atriz, fazendo do epistolário e de sua obra um lugar para as "memórias" de Marta e Pirandello juntos, luz e sombra de sua arte: "Se eu ainda estou vivo, se continuo ainda a trabalhar, é por sua causa. Nem uma coisa nem outra seriam possíveis se não fosse por Você" ${ }^{5}$

Paraalém destecenáriopassional,Marta Abba representou a possibilidade concreta de fusão entre sua técnica dramatúrgica e a fisicalidade do ator. O diálogo criativo que se estabeleceu entre o dramaturgo e a

5 Luigi Pirandello, Lettera a Marta Abba, op. cit., p. 245 (carta de 28 de julho de 1929). No dia seguinte Pirandello escreve a última carta antes de viajar de Berlim para a Itália e se encontrar com Marta. Ele volta a escrever para ela somente em 13 de setembro de 1929; data de seu retorno à Berlim. Já as cartas de Marta ao Maestro, referentes ao ano de 1929, foram quase todas perdidas, sobrevivendo as posteriores à data de 12 de setembro de 1929. atriz, iniciado na criação do Teatro de Arte e finalizado somente com a morte do escritor, proporcionou uma grande mudança de concepção nas ideias do dramaturgo sobre a relação ator/personagem. Por exemplo, em Sei personaggi Pirandello coloca em evidência, já que mostrado explicitamente na própria estrutura dramática, uma espécie de antagonismo insuperável entre estes dois elementos: a companhia de atores e o mundo dos personagens. Os atores seriam os responsáveis por degradar a autenticidade e a poesia do personagem, traindo a obra artística idealizada pelo poeta. Com Marta Abba, a problemática relação ator/personagem, sugerida pela lógica pirandelliana como irremediável, ganha uma nova visão. $\mathrm{O}$ impasse entre o mundo fantástico e o mundo material do palco encontra na atriz uma via de escape. Da condenação inicial se constata assim uma redenção final: o corpo da atriz, a sua dimensão material-corpórea, se transforma no meio indispensável para evocar o personagem ao palco, e o êxito final do processo será a absoluta possessão do corpo do intérprete. Na visão do último Pirandello, o teatro encontra suajustificativa no encontro "mágico" da arte do ator com o mundo abstrato do personagem.

O personagem-atriz, metáfora de Marta Abba, por sua especificidade, estabelece no teatro, mais do que qualquer outro, uma significativa interação entre o mundo real e o mundo do palco. Com Ilse, de I giganti della montagna, o personagem-atriz atinge seu estado puro. Destacada da vida, a atriz, que tem como missão levar a palavra do poeta aos homens, realiza sua projeção no mundo fantástico da arte: sua ascensão espiritual não advém de uma maternidade fisiológica, como as outras mulheres pirandellianas, mas de uma maternidade estética; o que para o autor significa um aperfeiçoamento da mulher comum. A peça, deixada sem conclusão, define o teatro, fundamentalmente enquanto arte do ator, como uma arte frágil que pertence ao seu tempo, ao sistema de produção de sua época, não havendo assim nenhuma 
garantia para a existência do espetacular, ou melhor, para a existência do teatro de Pirandello e Marta juntos. Como se pode ver no último quadro de I giganti, Cotrone, mais uma das encarnações de Pirandello, diz a Ilse, imagem fantasmática da atriz, que o seu poder termina ali, no exato momento em que a obra de arte precisa ser transformada em vida, no momento em que ela deixa o espaço de criação do poeta e se projeta na ação do palco, com a participação do público. Mas Ilse quer que a obra do poeta viva lá em meio aos homens. Sem uma resposta definitiva em relação ao destino da atriz, a última fala dos atores, ao ouvir o barulho dos cavalos dos gigantes que descem a montanha, será: eu tenho medo! Eu tenho medo!

Um pouco antes do barulho dos cavalos dos gigantes, Cotrone pede para Ilse representar La favola del figlio cambiato (um outro texto de Pirandello). Assim que a atriz começa a interpretar sua parte, a cena se materializa diante dela. Por um milagre, por um prodígio da fantasia, surgem dois personagens, duas aparições, que começam a representar junto com Ilse a Favola, e é o próprio Cotrone quem explica para Ilse: "Para nós é suficiente imaginar, e rapidamente as imagens se fazem vivas, de si mesmas. Basta que alguma coisa esteja bem viva em nós, que ela se auto-representa, pela virtude espontânea de sua própria vida". Segundo Vicentini (1993), se a magia de Cotrone, como a animação de fantoches não tem uma explicação plausível, é porque seu poder não se reduz a simples técnica de um prestidigitador, isto é, ele não se utiliza de instrumento e corpos materiais para criar seus fantasmas. Cotrone "projeta entorno de si os caracteres próprios do sonho, e trabalha prevalentemente com a manipulação de imagens" (1993, p.200201). Tudo é da natureza da imagem: a procissão do Angelo Centuno; as visões que perseguem os atores da vila durante a noite; asfiguras dosatoresque seencontram com os fantoches, após abandonarem seus corpos durante o sonho; as duas aparições que interpretam junto com a condessa uma cena da peça. Os poderes de Cotrone são da natureza da "desmaterialização". No mundo mágico da vila, entre seus azarados, os personagens podem aparecer, como na fantasia do autor, sem que existam corporalmente. A arte torna-se assim pura imagem e visão evanescente. Mas, esta concepção de arte se mostrará profundamente perigosa para a existência do teatro: destacado do público e das formas de organização características de sua própria época, o teatro anula a sua capacidade operativa, perde sua vocação prática.

Evadindo-se do confronto com a realidade material, o teatro se reduz em pura imagem, e finalmente deixa de existir: "Cotrone e o mundo mágico dos azarados não constituem uma solução real ao problema do teatro na sociedade industrial da máquina e do cinema e nem mesmo uma alternativa"; dirá Vicentini (1993, p. 2002). E o Pirandello desta última fase consegue reconhecer que a principal característica do teatro, aquilo que de fato se constitui em um procedimento mágico, é seu poder de canalizar, introduzir as criações fantásticas da arte no mundo material dos homens: o teatro é a arte que consegue unir de modo inseparável as imagens (as visões e as intuições) com a matéria (o corpo do intérprete, os mecanismos da cena). No entanto, Cotrone pede que Ilse represente apenas ali, na vila habitada pelos fantasmas. Ora, na verdade o que o mago está pedindo é que ela deixe de fazer teatro, pois fazer teatro é justamente enfrentar os problemas, as dificuldades, as circunstâncias concretas e as características históricas de sua própria época. O teatro só existe se enfrentar os Gigantes da Montanha. Esta é uma necessidade do teatro, sua vocação material. E Ilse deve estar preparada para isso. Mas, o próprio autor ainda hesitava diante desta escolha obrigatória. O terceiro passo, inevitável, em direção ao conflito final, jamais foi executado por Pirandello. O que se sabe é que o encontro final de Ilse com os gigantes 
seria, no imaginário pirandelliano, um evento trágico. A atriz seria assassinada em sua tentativa de realizar o teatro, isto é, de realizar o prodigioso contato entre a imaginação fantástica do poeta com as circunstâncias do mundo material; o que, de qualquer modo, não significa uma garantia para a sobrevivência do teatro.

Como Ilse, Marta via o teatro como a única forma de vida possível e, por isso, como descreve Pietro Frassica, organizador do epistolário Abba, ela nunca se dispôs a fazer muitas concessões ao mundo dos empresários e dos agentes teatrais. Protestando e denunciando o sistema de truste que imperava na Itália, que excluía sistematicamente as companhias que trabalhavam por conta própria, Marta Abba termina por ganhar muitos inimigos. $\mathrm{E}$ se a atriz havia construído um estilo de interpretação muito distinto das outras atrizes de sua época, inusitado até, isso facilmente foi tachado como uma interpretação fria, cerebral, e excessivamente "livre", isto é, sem controle. Rebelde a todas as convenções, a atriz pode ser considerada tão revolucionária quanto Pirandello. Como o escritor, ela também não se adaptava ao seu tempo e a estrutura do ambiente teatral italiano. Mas se a palavra escrita do poeta pode ultrapassar o tempo, sua época, e até mesmo o próprio poeta, a arte de uma atriz está irremediavelmente presa em um tempo eespaço determinados. O julgamento de sua arte sempre será feito pela cultura e pelos homens de sua época, o que equivale a dizer que a arte da atriz é prisioneira das circunstâncias de seu próprio tempo: "'I giganti della montagna' foi escrito para sublimar o tormento $\mathrm{e}$ o martírio da atriz com todo o seu fardo de poesia, que - neste caso particular - se chama na vida 'Marta Abba'"."

Seomundo da cenaedos atoresfascinou Pirandello, como realmente foi verdade,

6 Marta Abba em carta inédita a Lucio Ridenti, diretor da revista // Dramma (carta de 04 de março de 1960). 0 documento encontra-se disponível na biblioteca do Centro Studi del Teatro Stabile di Torino. a possibilidade de realizar plenamente o contato entre o mundo fantástico de sua imaginação com as circunstâncias do mundo do palco, lhe veio com Marta abba. Isso não significa dizer que não exista mais nenhuma tensão entre as realidades ou mesmo que não haja mais a possibilidade do fracasso desta missão. Embora recuperado em sua força original, como produtor de realidades, mais "reais" do que aquelas fabricadas pelo mundo cotidiano, o teatro, visto enquanto um procedimento mágico, não possui nenhuma garantia de sobrevivência. Se ao final de seu percurso artístico, Pirandello não via mais o teatro como uma arte impossível, ele a vivencia como uma arte frágil e demasiadamente suscetível ao seu tempo, isto é, às formas de produção e de organização práticas de sua época e às características da própria sociedade. Pois o teatro não é só a invenção da cena, ele só existe em confronto com sua realidade material, ele tanto pode florescer como sucumbir ou mesmo desaparecer, e novamente renascer em outro tempo, em outra lógica de produção. Logo, não existe para o teatro nenhum plano realmente seguro de continuidade. Em função deste diagnóstico, nem pessimista e nem otimista, mas de uma incrível lucidez, Pirandello não conseguiu concluir I giganti della montagna, adiando ao máximo sua solução final. Talvez ainda esperasse, para os últimos anos de sua vida, alguma mudança dos tempos que pudesse trazer uma nova perspectiva, menos hostil, a existência de seu teatro, um teatro feito fundamentalmente para Marta Abba.

\section{Referências bibliográficas}

ABBA, Marta. Caro Maestro... Lettere a Luigi Pirandello (1926-1936). A cura di Pietro Frassica. Milano: Mursia, 1994. 406 p.

Un'attrice allo specchio, come sono nella vita e come vivo nell'arte. Gazzetta del Popolo, 16 gennaio 1931, p. 03. ALONGE, Roberto. Madri, baldracche, amanti, la figura femminile nel teatro di Pirandello. 
Milano: Costa \& Nolan, 1997. 137 p. Luigi Pirandello, il teatro del XX secolo. Bari: Editori Laterza, 1997. 180 p.

BINI, Daniela. Epistolario e teatro, scrittura dell'assenza e sublimazione dell' erotismo. Il Castello di Elsinore, Torino, DAMS, anno XI, 33, 1998. p. 32-46.

GUINSBURG, Jacó (Org). Pirandello: do teatro no teatro. São Paulo: Perspectiva, 1999. $405 \mathrm{p}$.

JOUANNY, Sylvie. L'actrice et ses doubles. Figures et representations de la femme de spectacle à la fin du XIX siècle. Genève: DROZ, 2002. 442 p.

LETIZIA, Annarita. Le ultime figlie di pirandello. Angelo di Fuoco, anno III, n. 05, Torino, DAMS, 2004. p. 07-54.

. Pirandello; LIETTA, Marta.

Angelo di Fuoco, Ano II, 4, 2003. p. 05-51.

PIRANDELLO, Luigi. Maschere nude. A cura di Italo Borzi e Maria Argenziano. Roma: I Mammuti, 2005. 1274 p.

Lettere a Marta Abba. A cura di Benito

Ortolani. Milano: Mondadori, 1995. 1656 p. . Illustratori, attori e traduttori. In: Saggi, poesie e scritti varii, a cura di Manlio Lo Vecchio Musti. Vol.6, 2. ed. Milano: Mondadori, 1965. p. 209-224.

RIBEIRO, Martha. Luigi Pirandello: um teatro para Marta Abba. São Paulo: Perspectiva, 2010. VICENTINI, Claudio. Pirandello. Il disagio del teatro. Venezia: Marsilio editori, 1993. 217 p. 